\title{
Surgical anatomy of the aortic root: Implication for valve-sparing reimplantation and aortic valve annuloplasty
}

\author{
Laurent de Kerchove, MD, PhD, ${ }^{\mathrm{a}, \mathrm{b}}$ Ramadan Jashari, MD, ${ }^{\mathrm{c}}$ Munir Boodhwani, MD, MMSc, ${ }^{\mathrm{d}}$ \\ Khanh Tran Duy, Ir, PhD, ${ }^{\mathrm{e}}$ Benoit Lengelé, MD, PhD, ${ }^{\mathrm{f}}$ Pierre Gianello, MD, PhD, ${ }^{\mathrm{g}}$ \\ Zahra Mozala Nezhad, MD, ${ }^{\mathrm{a}}$ Parla Astarci, MD, PhD, ${ }^{\mathrm{a}}$ Philippe Noirhomme, MD, ${ }^{\mathrm{a}}$ and \\ Gebrine El Khoury, MD
}

\begin{abstract}
Background: To enhance the reproducibility of aortic valve-sparing reimplantation and annuloplasty, we analyzed the topographic relationship between the ventriculoaortic junction (VAJ), basal ring (BR), and sinotubular junction (STJ). The root base thickness is also quantified.

Method: Fifty-eight fresh human aortic valves were analyzed. The root was dissected to the limit where the aortic wall terminates into the cardiac structures (VAJ). Root height was measured externally from the STJ to the VAJ and internally from the STJ to the BR defined as the plane passing through the cusps nadir. The root base thickness was measured at the BR and orthogonal to the internal wall; except at the right coronary sinus, where it was measured between the BR internally and the VAJ externally. Measurements were taken at the middle of the 3 sinuses and commissures.
\end{abstract}

Results: The VAJ is at the same level as the BR from the noncoronary sinus $(-0.1$ $\pm 0.9 \mathrm{~mm})$ to the left coronary sinus $(0.5 \pm 1.3 \mathrm{~mm})$; it is above the BR from the left/right commissure $(4.6 \pm 1.4 \mathrm{~mm})$ to the right/non commissure $(2.5 \pm 1.6$ $\mathrm{mm})$. The external root height was highest at the non/left commissure $(21.5 \pm$ $2.6 \mathrm{~mm})$ followed by the right/non commissure $(19.2 \pm 2.3 \mathrm{~mm})$ then the left/right commissure $(15.7 \pm 2.2 \mathrm{~mm})(P<.05)$. The mean root base thickness was 3.2 $\mathrm{mm}$, ranging from $1 \pm 0 \mathrm{~mm}$ at the left/non commissure to $6.2 \pm 1.2 \mathrm{~mm}$ at the right coronary sinus $(P<.001)$.

Conclusions: The VAJ is not planar; it is above the level of the BR from the left/ right to the right/non commissure. As a consequence, the external height of the non/left commissure is greater than the other 2 commissures. These findings should be taken into consideration when performing aortic valve-sparing reimplantation or external annuloplasty. (J Thorac Cardiovasc Surg 2015;149:425-33)

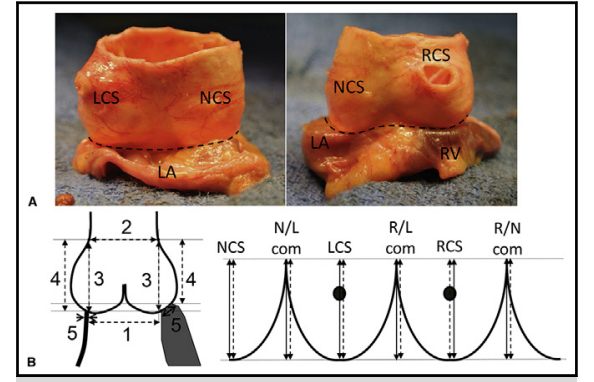

Surgical anatomy of the aortic root.

Central Message

Measurements in 58 fresh aortic roots determined that the external height of the non/left commissure was greater than the other two.

Clinical Relevance

These findings are important for aortic annuloplasty techniques, particularly valve-sparing reimplantation and external ring annuloplasty in which the graft or the ring is fixed around the base of the root. Incomplete proximal root dissection will impede placement of the device down to the basal root level. However, these studies show that dissection to the basal root is possible to secure external fixation.

\footnotetext{
From the Pôle de Recherche Cardiovasculaire, ${ }^{\text {a }}$ Institut de Recherche Expérimentale et Clinique, Université Catholique de Louvain, Brussels, Belgium; Division of Cardiothoracic and Vascular Surgery, ${ }^{\mathrm{b}}$ Cliniques Universitaires Saint-Luc, Brussels, Belgium; Europen Homograft Bank, ${ }^{\mathrm{c}}$ Military Hospital, Brussels, Belgium; Division of Cardiac Surgery, ${ }^{\mathrm{d}}$ University of Ottawa Heart Institute, Ottawa, Ontario, Canada; Institute of Mechanics, ${ }^{\text {e }}$ Materials and Civil Engineering, Université Catholique de Louvain, Louvain-la-Neuve, Belgium; Pôle Morphologie $^{\mathrm{f}}$ and Pôle de Chirurgie Expérimentale et Transplantation, ${ }^{\mathrm{g}}$ Institut de Recherche Expérimentale et Clinique, Université Catholique de Louvain Brussels, Belgium. Disclosures: Authors have nothing to disclose with regard to commercial support. Received for publication July 29, 2014; revisions received Sept 5, 2014; accepted for publication Sept 15, 2014; available ahead of print Oct 24, 2014

Address for reprints: Laurent de Kerchove, MD, PhD, Division of Cardiothoracic and

Vascular Surgery, Cliniques Universitaires St-Luc, Ave Hippocrate 10, 1200 Brussels, Belgium (E-mail: laurent.dekerchove@uclouvain.be).

$0022-5223 / \$ 36.00$

Copyright (c) 2015 by The American Association for Thoracic Surgery

http://dx.doi.org/10.1016/j.jtcvs.2014.09.042
}

Aortic valve-sparing root replacement and repair are emerging more and more as an advantageous alternative to replacement with composite grafts or prosthetic valves. However, reconstructive surgery of the aortic valve is technically more demanding compared with replacement and needs in-depth knowledge of the anatomy of the aortic valve and the root. Most anatomical studies on the aortic valve have been performed before the era of aortic valve repair, which explain why several measurements of importance for valve repair have been poorly analyzed if at all. ${ }^{1-7}$ The lack of quantitative data on the repair-oriented anatomy of the aortic valve impairs the reproducibility and standardization of surgical techniques. 


$$
\begin{aligned}
& \text { Abbreviations and Acronyms } \\
& \text { AV }=\text { aortic valve } \\
& \text { BR }=\text { basal ring } \\
& \text { LCS }=\text { left coronary sinus } \\
& \text { NCS }=\text { noncoronary sinus } \\
& \text { RCS }=\text { right coronary sinus } \\
& \text { STJ }=\text { sinotubular junction } \\
& \text { VAJ }=\text { ventriculoaortic junction }
\end{aligned}
$$

It has been demonstrated that an untreated large ventriculoaortic junction (VAJ) has a negative impact on repair durability; and noncircumferential annuloplasty, like the commissural annuloplasty stitch described by Cabrol, seems inadequate to provide stable reduction of a large VAJ over time..$^{8-12}$ In consequence, a variety of circumferential annuloplasty techniques (eg, internal or external ring, suture annuloplasty) are actually in the experimental or clinical phase of development. ${ }^{13-16}$ These techniques have potentially different effects on aortic valve function and root geometry, which suggests that aortic valve and root anatomy need to be reconsidered to make appropriate use of annuloplasty techniques. $^{17}$

For external ring annuloplasty and for the valve-sparing reimplantation technique, the base of the aortic root must be dissected free to allow the ring or the graft to be placed, ideally at the level of the basal ring (BR), defined as the plane passing through the nadir of the aortic cusps. However, the instigators of the valve-sparing reimplantation technique have reported that the BR level may not be reachable for the entire root circumference in all cases. ${ }^{18,19}$ The limit of proximal dissection of the aortic root corresponds to the external aspect of the VAJ, also defined as the zone where the ventricular structures join the wall of the aortic root. In the early 1990s, Anderson and colleagues ${ }^{5}$ described the anatomy the VAJ as a relatively plane circle passing through the lower third of the 3 sinuses of Valsalva, thus crossing the cusp insertion above the plane of the BR. Since this report, he and his collaborators nuanced the description of the VAJ placing it at the level of the BR or above where the cusp insertion lines cross the ventricular myocardium. ${ }^{7,20}$ This last configuration concerns the right and left coronary cusp. The resulting muscular inclusion at the base of the sinus of Valsalva varies in size from heart to heart and its width in humans has rarely been measured. $^{1,20}$

In this anatomic study, our aim was to analyze quantitatively the topographic relationship between the VAJ and the BR in the human aortic valve. In addition, we sought to quantify the thickness of the VAJ at different levels of the root circumference including the width of the muscular inclusion at the base of the right coronary sinus (RCS).

\section{MATERIALS AND METHODS \\ Origin and Management of the Specimen}

We analyzed 58 fresh aortic roots obtained from a homograft bank $(n=41)$ or from donated cadavers $(n=17)$. The specimens obtained from the homograft bank had been rejected for clinical use and therefore allocated for research. All specimens were tricuspid aortic valves. Each specimen was harvested initially as a bloc of tissue including 3 to $4 \mathrm{~cm}$ of heart tissue around the aortic root. No chemical fixation was applied to the specimens, which were cryopreserved between the different phases of root preparation and the measurements. Root preparation and measurements were performed by 1 senior cardiac surgeon (L.D.K.).

The general characteristics of the specimen were recorded including donor age, gender, and the presence of calcification (graded as mild, moderate, or severe). Valve or root calcifications were not considered as exclusion criteria.

The study was approved by the institutional ethics committee.

\section{Root Preparation}

All specimens were prepared similarly before the measurements were taken (Figure 1, A). The aorta was transected at the level of the sinotubular junction (STJ). Left ventricular outflow tract structures (anterior mitral leaflet and interventricular septum) were trimmed to leave 1 to $1.5 \mathrm{~cm}$ of tissue below the BR. Coronaries were cut at the ostia. The aortic root was dissected free from the surrounding cardiac structures, similar to the valve-sparing reimplantation technique. ${ }^{21}$ The root dissection was performed caudally to the limit where the heart structures terminate and give way to the wall of the aortic root. This limit was considered as the external aspect of the anatomical VAJ. A rim of 1 to $2 \mathrm{~cm}$ of tissue surrounding the base of the aortic root was preserved to maintain a clear demarcation of the VAJ (Figure 1, A).

\section{Root Measurements}

The measurements taken on the aortic root were the diameter of the left ventricular outflow tract at the level of the BR (BR diameter), the STJ diameter, the internal and external root height, and the root base thickness.

Measurements were taken with a dry point compass or a ruler at 6 points around the root circumference: the middle of the 3 commissures and the middle of the 3 sinuses of Valsalva (Figure 1, B). The diameters of the BR and STJ were taken from the inner to inner side of the ventricular or aortic wall. The external root height was measured from the STJ to the VAJ and the internal root height was measured from the STJ to the BR. The external root height was measured on the intact aortic root specimen; then the root was opened longitudinally at the middle of the non/left commissure to measure the internal root height (Figure 1,C). The BR level was defined as a plane passing through the ventricular side of the nadir of the aortic cusps. To measure the internal root height at the commissures, the BR level was marked on the specimen by tracing a mark at the middle of the straight line joining the nadir of adjacent cusps (Figure 1,C). The specimens were held in place to maintain a normal anatomic configuration but no additional tension was applied on the tissues to take the measurements. The difference between the internal and external root height was calculated to estimate the relative distance separating the BR level from the VAJ level. A positive difference between the internal and external root height indicates that the VAJ was above (distal to) the BR level; conversely, a negative difference indicates that the VAJ was below (proximal to) the BR level. A zero difference indicates that the VAJ and the BR were at the same level. Root base thickness was measured at the BR level and orthogonal to the wall of the left ventricular outflow tract. At the level of the RCS, root 
A
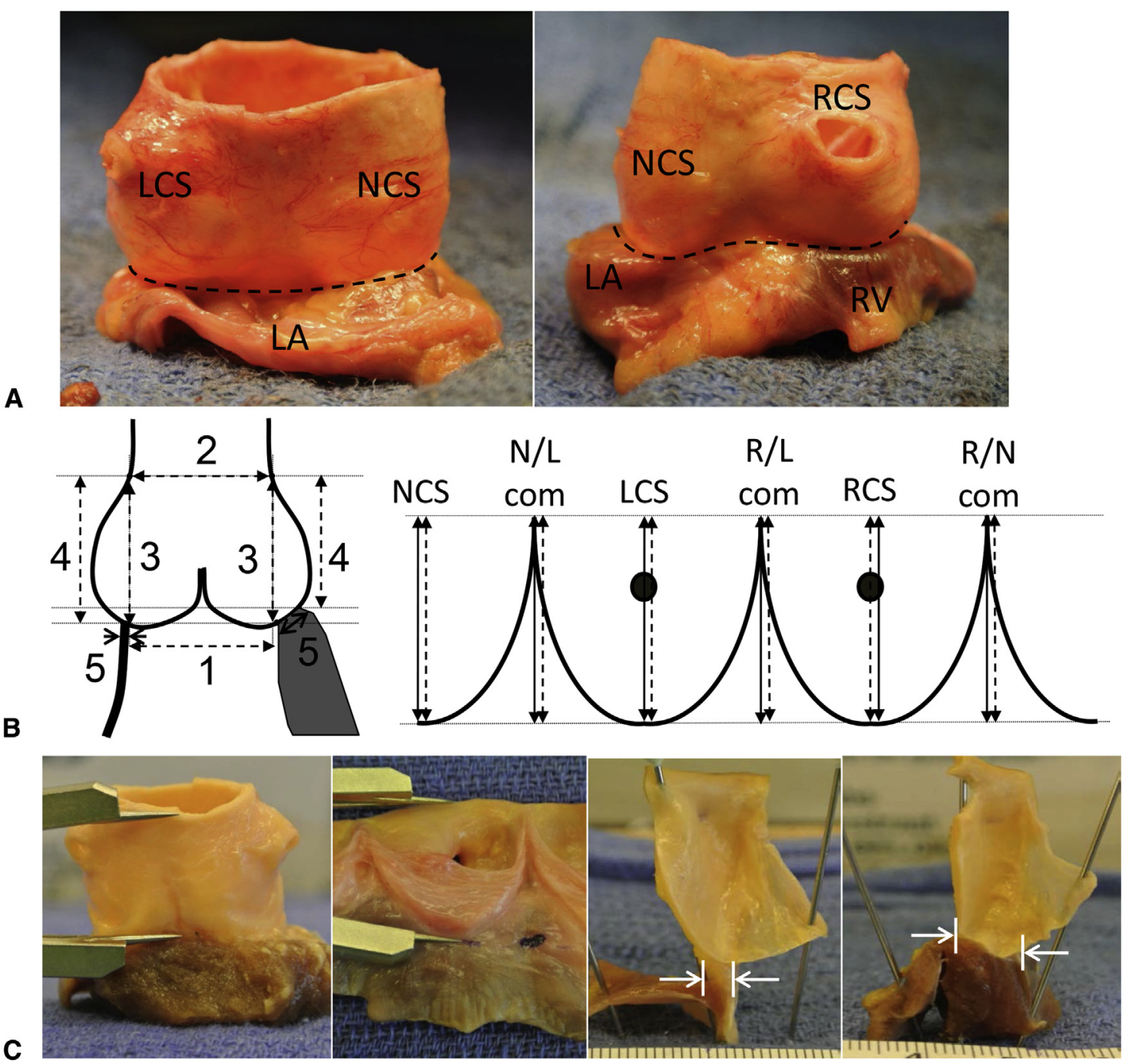

FIGURE 1. A, Preparation of the aortic root specimen. The external side of the aortic root was dissected free to the transition between the aortic wall and the heart structure; this anatomical landmark was defined as the ventriculoaortic junction (VAJ, dashed line); left panel, posterior view; right panel, anterior view. B, The different measurements taken on the aortic root (1, basal ring [BR] diameter; 2, sinotubular junction diameter; 3 and 4, internal and external root height; 5 , root base thickness). Measurements 3 to 5 were taken at the middle of each sinus of Valsalva and at each commissure. C, Left panels, measurement of the external and internal root height with a dry point compass. Right panels show how the root base thickness (distances between white arrows) was measured at the level of the BR, orthogonal to the internal wall except at the level of the RCS where the distance between the BR and the VAJ (muscular inclusion) was measured. $L C S$, Left coronary sinus; $N C S$, noncoronary sinus; $L A$, left atrium; $R C S$, right coronary sinus; $R V$, right ventricle; $N / L$ com, non/ left commissure; $R / L \mathrm{com}$, right/left commissure; $R / N$ com, right/non commissure.

base thickness was measured taking the absolute distance between the BR internally to the VAJ externally. This distance represents the width of the muscular inclusion at the base of the RCS (Figure 1, $B$ and $C$ ). Measurements were rounded to the nearest millimeter. The relative distances were also calculated for the root height, taking the internal root height of the left/non commissure as reference.

\section{Statistical Analysis}

Categorical variables are presented as percentages; continuous variables are presented as the mean \pm standard deviation. The range is indicated in brackets [ $\min ; \max$ ]. Normal distribution was checked for continuous variables. Comparison of the means was performed using the Student $t$ test. Comparison between categorical variables was performed using the
Fischer exact or $\chi^{2}$ test when appropriate. Statistical analyses were performed using SPSS 20 (SPSS, IBM Corp, Somers, NY).

\section{RESULTS \\ Root Characteristics}

Substantial differences were found in the donor characteristics and root size between donors from the homograft bank and cadaveric donors.

Overall, the mean age of the donors was $65 \pm 24$ years and $52 \%$ were men. Donors from the homograft bank were younger (mean age $55 \pm 24$ years; range, 31-69 years) and included more men (59\%) compared with cadaveric 
TABLE 1. Internal and external root height and wall thickness measurements in all specimens and by origin (homograft or donated cadaver)

\begin{tabular}{|c|c|c|c|c|c|c|c|c|c|c|c|c|}
\hline \multirow[b]{2}{*}{ Measurement } & \multicolumn{6}{|c|}{ Distance (mm) } & \multicolumn{6}{|c|}{$P$ value } \\
\hline & NCS & N/L com & LCS & $\mathrm{L} / \mathrm{R}$ com & RCS & $\mathrm{R} / \mathrm{N}$ com & $\begin{array}{c}\text { NCS vs } \\
\text { LCS }\end{array}$ & $\begin{array}{l}\text { LCS vs } \\
\text { RCS }\end{array}$ & $\begin{array}{l}\text { NCS vs } \\
\text { RCS }\end{array}$ & $\begin{array}{c}\text { N/L vs } \\
\text { L/R }\end{array}$ & $\begin{array}{c}\mathrm{L} / \mathrm{R} \text { vs } \\
\mathrm{R} / \mathrm{N}\end{array}$ & $\begin{array}{c}\text { N/L vs } \\
\text { R/N }\end{array}$ \\
\hline \multicolumn{13}{|c|}{ All specimens $(\mathrm{n}=58)$} \\
\hline $\begin{array}{l}\text { Internal root } \\
\text { height }\end{array}$ & $22.1 \pm 2.5$ & $21.8 \pm 2.4$ & $21.6 \pm 2.3$ & $20.3 \pm 2.3$ & $21.7 \pm 2.6$ & $21.7 \pm 2.7$ & $\mathrm{~ns}$ & $\mathrm{~ns}$ & $\mathrm{~ns}$ & $<.01$ & $<.01$ & $\mathrm{~ns}$ \\
\hline $\begin{array}{c}\text { External root } \\
\text { height }\end{array}$ & $22.2 \pm 2.7$ & $21.6 \pm 2.5$ & $21.1 \pm 2.4$ & $15.7 \pm 2.2$ & $19.3 \pm 2.5$ & $19.2 \pm 2.4$ & .02 & $<.01$ & $<.01$ & $<.01$ & $<.01$ & $<.01$ \\
\hline $\begin{array}{l}\text { Internal-external } \\
\text { difference }\end{array}$ & $-0.1 \pm 0.9$ & $0.3 \pm 1.2$ & $0.5 \pm 1.3$ & $4.6 \pm 1.4$ & $2.4 \pm 1.5$ & $2.5 \pm 1.6$ & $\mathrm{~ns}^{*}$ & ns* & $\mathrm{ns}^{*}$ & $<.01 *$ & $<.01^{*}$ & $<.01 *$ \\
\hline $\begin{array}{l}\text { Root base } \\
\text { thickness }\end{array}$ & $2.5 \pm 0.6$ & $1 \pm 0$ & $3.0 \pm 1.0$ & $3.9 \pm 1.1$ & $6.2 \pm 1.2$ & $2.8 \pm 1.6$ & $<.01$ & $<.01$ & $<.01$ & $<.01$ & .04 & .01 \\
\hline \multicolumn{13}{|c|}{ Homograft bank $(\mathrm{n}=41)$} \\
\hline $\begin{array}{l}\text { Internal root } \\
\text { height }\end{array}$ & $21.9 \pm 2.4$ & $21.8 \pm 2.3$ & $21.4 \pm 2.3$ & $20.1 \pm 2.0$ & $21.3 \pm 2.3$ & $21.5 \pm 2.6$ & $\mathrm{~ns}$ & $\mathrm{~ns}$ & ns & .01 & $<.01$ & $\mathrm{~ns}$ \\
\hline $\begin{array}{l}\text { External root } \\
\text { height }\end{array}$ & $21.9 \pm 2.7$ & $21.6 \pm 2.6$ & $20.8 \pm 2.4$ & $15.1 \pm 1.8$ & $19 \pm 2.4$ & $19 \pm 2.3$ & $\mathrm{~ns}$ & $<.01$ & $<.01$ & $<.01$ & $<.01$ & $<.01$ \\
\hline $\begin{array}{l}\text { Internal-external } \\
\text { difference }\end{array}$ & $0 \pm 0.9$ & $0.1 \pm 1.2$ & $0.6 \pm 1.5$ & $5 \pm 1.1$ & $2.4 \pm 1.3$ & $2.5 \pm 1.7$ & $\mathrm{~ns}^{*}$ & $\mathrm{~ns}^{*}$ & $\mathrm{~ns}^{*}$ & $<.01 *$ & $<.01 *$ & $<.01 *$ \\
\hline $\begin{array}{l}\text { Root base } \\
\text { thickness }\end{array}$ & $2.5 \pm 0.7$ & $1 \pm 0$ & $3.1 \pm 1.0$ & $4.9 \pm 0.9$ & $6.3 \pm 1.2$ & $3 \pm 1.7$ & $<.01$ & $<.01$ & $<.01$ & $<.01$ & .01 & $<.01$ \\
\hline \multicolumn{13}{|c|}{ Donated cadavers $(\mathrm{n}=17)$} \\
\hline $\begin{array}{l}\text { Internal root } \\
\text { height }\end{array}$ & $22.6 \pm 2.5$ & $22.1 \pm 2.8$ & $22.1 \pm 2.3$ & $20.6 \pm 2.9$ & $22.5 \pm 3.1$ & $22.2 \pm 3.1$ & $\mathrm{~ns}$ & $\mathrm{~ns}$ & ns & $\mathrm{ns}$ & ns & $\mathrm{ns}$ \\
\hline $\begin{array}{l}\text { External root } \\
\text { height }\end{array}$ & $23.2 \pm 2.7$ & $21.4 \pm 2.5$ & $21.7 \pm 2.5$ & $17.1 \pm 2.5$ & $20.1 \pm 2.6$ & $19.8 \pm 2.5$ & $\mathrm{~ns}$ & $\mathrm{~ns}$ & $<.01$ & $<.01$ & $<.01$ & $\mathrm{~ns}$ \\
\hline $\begin{array}{l}\text { Internal-external } \\
\text { difference }\end{array}$ & $-0.5 \pm 0.9$ & $0.6 \pm 1.3$ & $0.4 \pm 0.9$ & $3.6 \pm 1.5$ & $2.4 \pm 2$ & $2.4 \pm 1.3$ & $\mathrm{~ns}^{*}$ & $\mathrm{~ns}^{*}$ & $\mathrm{~ns}^{*}$ & $<.01^{*}$ & $<.01^{*}$ & $.02 *$ \\
\hline $\begin{array}{l}\text { Root base } \\
\text { thickness }\end{array}$ & $2.7 \pm 0.5$ & $1 \pm 0$ & $2.8 \pm 0.8$ & $3.2 \pm 0.6$ & $6 \pm 1$ & $2 \pm 1.4$ & $\mathrm{~ns}$ & $<.01$ & $<.01$ & $<.01$ & .046 & .01 \\
\hline
\end{tabular}

NCS, Noncoronary sinus; $N / L$ com, non/left commissure; $L C S$, left coronary sinus; $L / R$ com, left/right commissure; $R C S$, right coronary sinus; $R / N$ com, right/non commissure. *Compares internal versus external root height at each of the 6 locations respectively (NCS, non/left commissure, LCS, left/right commissure, RCS, right/non commissure).

donors (mean age $89 \pm 6$ years; $P<.001$; range, $76-99$ years; $35 \%$ male, $P=.19$ ).

As a result of age differences, specimens from cadaveric donors had greater frequency and severity of cusp calcification $(35 \%$, all moderate or severe, vs $5 \%$, all mild: $P=.006)$ and larger STJ diameter $(25.7 \pm 2.4 \mathrm{~mm}$ vs 21 $\pm 2.5 \mathrm{~mm} ; P<.001)$. The BR diameter was similar in the specimens from cadavers or the homograft bank (22.6 \pm $2.6 \mathrm{~mm}$ vs $23 \pm 2 \mathrm{~mm} ; P=.55$ ).

\section{Root Measurements}

Difference between internal and external root height. The internal root height was similar to the external root height at the noncoronary sinus (NCS), non/left commissure, left coronary sinus (LCS) $(P=\mathrm{ns})$; however, the internal root height was significantly greater than the external root height at the left/right commissure, the RCS, and the right/non commissure $(P<.001)$ (Table 1 , Figure 2, $A)$. The differences between the internal and external root heights showed that the VAJ is at the same level as the $\mathrm{BR}$ at the NCS (internal - external root height $=-0.1 \pm$ $0.9 \mathrm{~mm}[-3 ;+2])$, non/left commissure $(+0.3 \pm 1.2 \mathrm{~mm}$
$[-3 ;+5])$ and $\operatorname{LCS}(+0.5 \pm 1.3 \mathrm{~mm}[-2 ;+5])$; however, the VAJ is above the BR level at the left/right commissure $(+4.6 \pm 1.4 \mathrm{~mm}[+2 ;+7]), \mathrm{RCS}(+2.4 \pm 1.5 \mathrm{~mm}[-1 ;$ $+7])$, and the right/non commissure $(+2.5 \pm 1.6 \mathrm{~mm}$ $[-1 ;+6]$ ) (Figure 2). At the left/right commissure, the VAJ was at least $4 \mathrm{~mm}$ above the BR level in $74 \%$ and 5 $\mathrm{mm}$ above the BR in $57 \%$. At the RCS, the VAJ was at least $4 \mathrm{~mm}$ above the BR in $15 \%$ and $5 \mathrm{~mm}$ above the BR in $7 \%$. At the right/non commissure, the VAJ was at least $4 \mathrm{~mm}$ above the BR in $22 \%$ and $5 \mathrm{~mm}$ above the BR in $10 \%$.

Root asymmetry. The internal root height at the non/left commissure and right/non commissure was slightly greater compared with the left/right commissure $(P<.01)$. The internal root heights were similar for the 3 sinuses $(P=\mathrm{ns})$ (Table 1). The external root height at the commissures was greatest at the left/non commissure followed by the right/non commissure, then the left/right commissure $(P<.01)$. The external root height at the sinuses was greatest at the NCS followed by the LCS, then the RCS $(P=.02)$ (Table 1, Figure 3$)$.

In terms of relative distance, the internal root heights were 1, 0.93, and 0.99 for non/left, left/right, and right/non commissures, respectively, and 0.99, 0.99, and 1.01 for the LCS, 


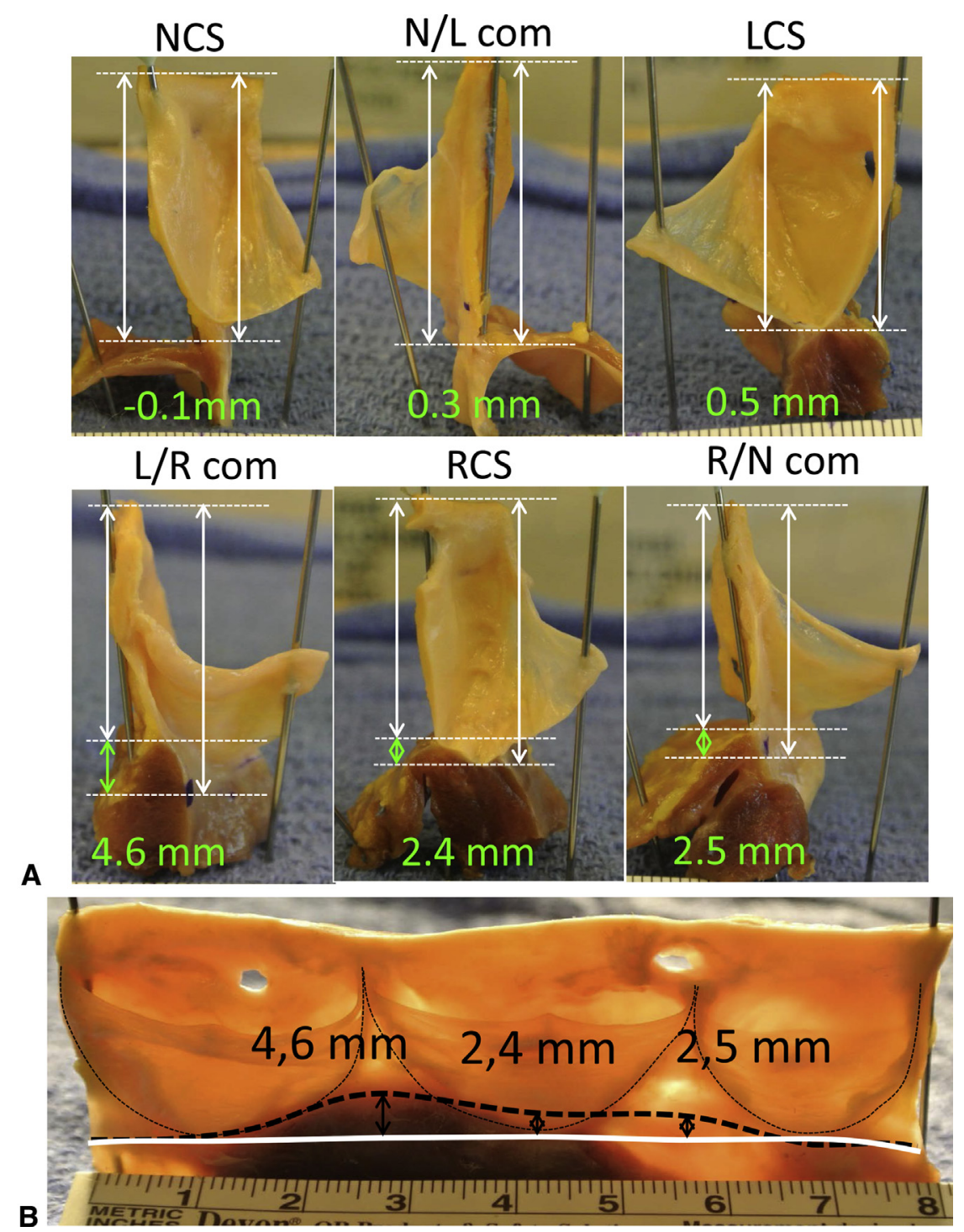

FIGURE 2. A, The differences between the internal root height (sinotubular junction to basal ring) and the external root height (sinotubular junction to ventriculoaortic junction) at the 3 sinuses and 3 commissures. B, Intraluminal view of a longitudinally opened aortic root; topographic relationship between the BR (continuous white line) and VAJ (dashed black line). NCS, Noncoronary sinus; N/L com, non/left commissure; $L C S$, left coronary sinus; $L / R$ com, left/ right commissure; $R C S$, right coronary sinus; $R / N \mathrm{com}$, right/non commissure.

RCS, and NCS, respectively. The relative external root heights were $0.99,0.72$, and 0.88 for the non/left, left/right, and right/non commissures, respectively, and 0.97, 0.89, and 1.02 for the LCS, RCS, and NCS, respectively.

Root base thickness. The root base thickness was relatively thin at the level of the right/non commissure, NCS, non/left commissure, and the LCS, and thicker at the level of the left/right commissure and the RCS (Figure 4). The mean width of the muscular inclusion at the RCS was $6.2 \pm 1.2 \mathrm{~mm}$ [4; 9]. Overall, the mean root base thickness was $3.2 \pm 0.6 \mathrm{~mm}$.

\section{Subgroup Analysis}

Few differences were observed comparing older specimens (donated cadavers) with younger specimens (homograft donors). The external root height of the left/ right commissure was greater in older specimen group compared with younger specimen $(17.1 \pm 2.5 \mathrm{~mm}$ vs 15.1 $\pm 1.8 \mathrm{~mm} ; P=.001)$, resulting in a somewhat higher VAJ level in the younger specimen group $(3.6 \pm 1.5 \mathrm{~mm}$ vs $5 \pm 1.1 \mathrm{~mm} ; P<.001)$. The root base thickness was thinner at the level of the left/right commissure in the older specimen group compared with the younger specimens (3.2 $\pm 0.6 \mathrm{~mm}$ vs $4.9 \pm 0.9 \mathrm{~mm} ; P=.01)$. Mean wall thickness was $3.1 \pm 0.4 \mathrm{~mm}$ in the older specimen versus $3.3 \pm 1 \mathrm{~mm}$ in the younger specimens $(P=.34)$.

Among the 58 specimens, those with a large BR diameter ( $\geq 25 \mathrm{~mm}, \mathrm{n}=13$; mean, $26 \mathrm{~mm}[25 ; 30]$ ) were compared with those with a small $\mathrm{BR}$ diameter $(<25 \mathrm{~mm}, \mathrm{n}=45$; 


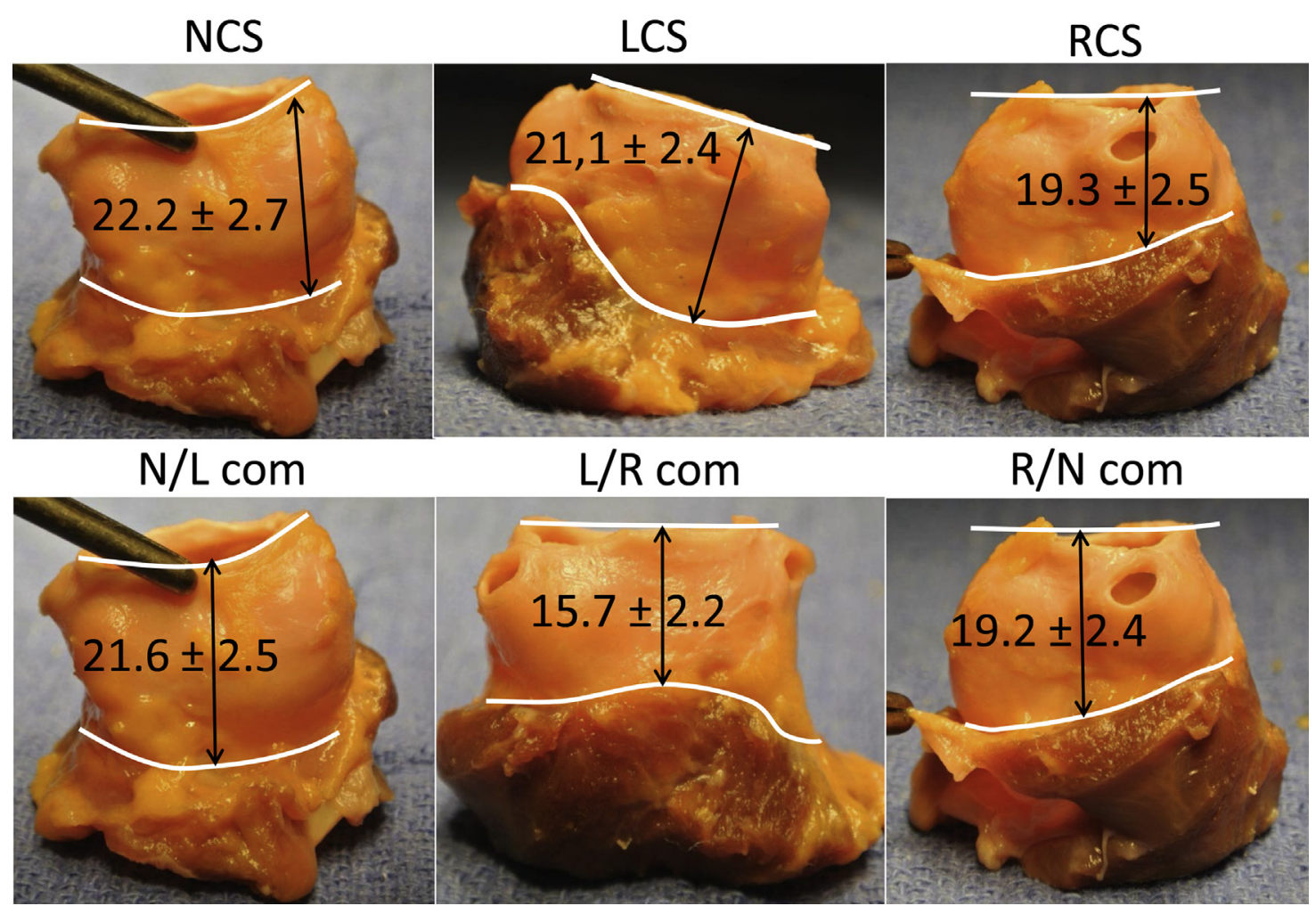

FIGURE 3. Asymmetry of the external aspect of the aortic root; external root heights are represented at the 3 sinuses and 3 commissures. NCS, Noncoronary sinus; $L C S$, left coronary sinus; $R C S$, right coronary sinus; $N / L$ com, non/left commissure; $L / R$ com, left/right commissure; $R / N$ com, right/non commissure.

mean, $22 \mathrm{~mm}[18 ; 24])$. Mean age was similar (65 years) in each BR group but the large BR group contained relatively more male specimens $(70 \%$ vs $49 \% ; P=.2)$. The STJ was significantly larger in the large BR group compared with the small BR group $(24.2 \pm 2.9 \mathrm{~mm}$ vs $21.9 \pm 3.2 \mathrm{~mm}$; $P=.028)$. At all levels of root circumference, the internal and external root heights were greater in the large BR group $(P<.01)$. The VAJ levels were similar between the large and small BR groups at the NCS, non/left commissure, and LCS $(P=\mathrm{ns})$, but were greater in the large BR group at the left/ right commissure, RCS, and right/non commissure (5.4 \pm $1.5 \mathrm{~mm}$ vs $4.4 \pm 1.3 \mathrm{~mm}, P=.02 ; 3 \pm 1.9 \mathrm{~mm}$ vs $2.2 \pm$ $1.3 \mathrm{~mm}, P=.08 ; 3.2 \pm 1.7 \mathrm{~mm}$ vs $2.2 \pm 1.5 \mathrm{~mm}$, $P=.04$, respectively). The mean root base thickness was $3.5 \pm 0.8 \mathrm{~mm}$ in the large BR group versus $3.2 \pm 0.4 \mathrm{~mm}$ in the small BR group $(P=.15)$.

\section{DISCUSSION}

In this study, we quantitatively analyzed the anatomy of the aortic root base in tricuspid aortic valves. We found that the VAJ is not a planar circle strictly above the BR as initially proposed by Anderson and colleagues. ${ }^{5}$ Rather, the junction is a three-dimensional curvilinear circle partially at the level of the BR and partially above, which is in accordance with the nuanced definition of the
VAJ given by Anderson and colleagues a couple of years after their first description. ${ }^{7}$ On the left and anterior side of the aortic root base (left/right commissure, RCS, right/non commissure), external root dissection does not reach the level of the BR because the ventricular myocardium and the right atrium merge with the root wall 2.4 to $4.6 \mathrm{~mm}$ above the BR level. On the right and posterior side of the aortic root (NCS, non/left commissure, LCS), external root dissection reaches the level of the BR because the left atrium merges with root wall at the level of the BR. The particular tridimensional aspect of the VAJ induces a certain asymmetry of the external root height; the non/left commissure is higher than the others. We also found that the thickness of the root base was variable along the root circumference; the overall mean thickness was $3.2 \mathrm{~mm}$. The mean width of the muscular inclusion at the base of RCS was $6.2 \mathrm{~mm}$. Subgroup comparisons showed relatively similar root base anatomy between young versus older specimens. In the specimens with large BR diameter, the VAJ was slightly higher above the BR level from the left/right commissure to the right/non commissure compared with specimens with small BR diameter.

A review of the literature reveals that no other studies report quantitative assessment of the topographic relationship between the VAJ and the BR and no studies have 


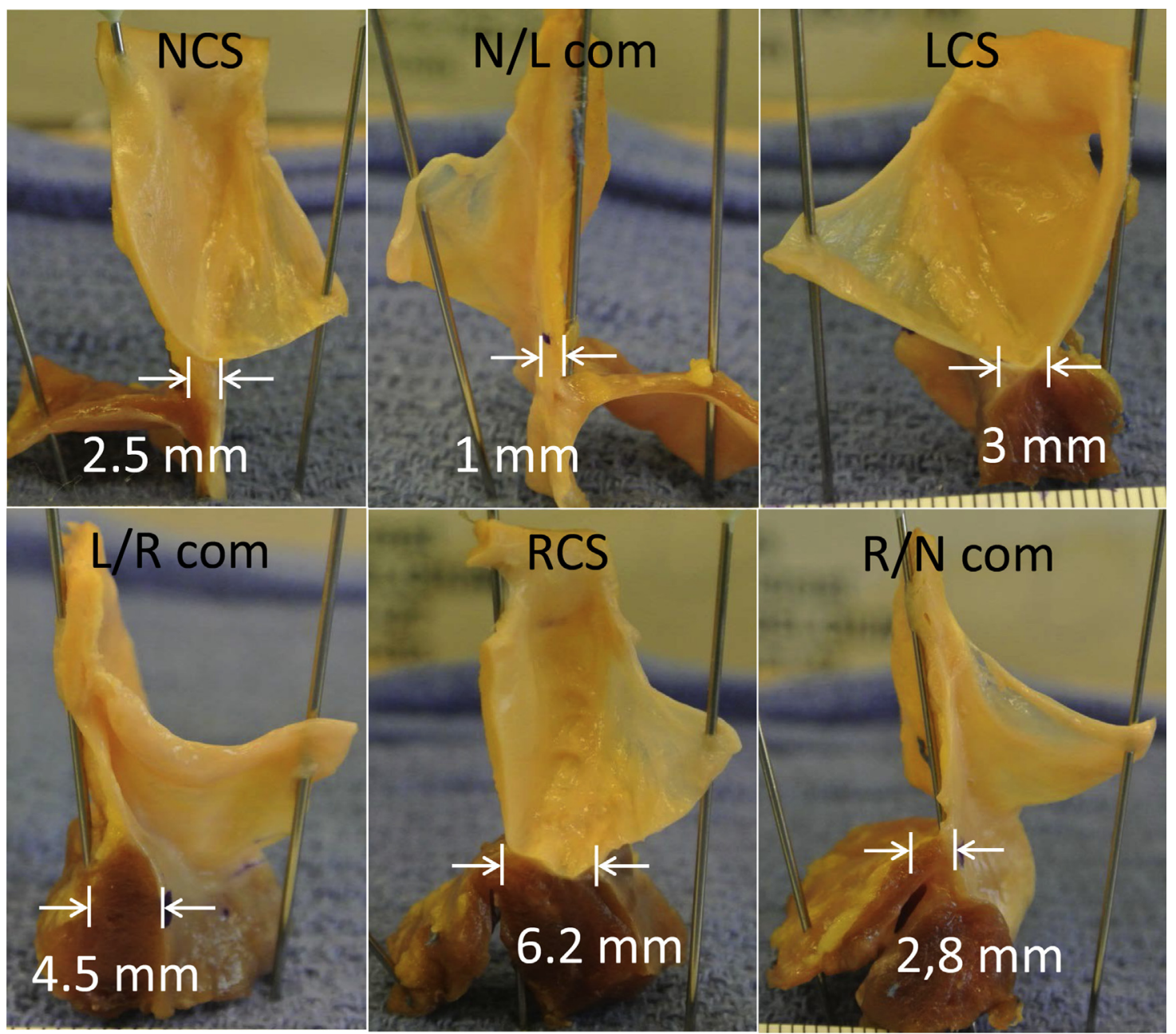

FIGURE 4. The root base thickness at the 3 sinuses and 3 commissures. $N C S$, Noncoronary sinus; $N / L$ com, non/left commissure; LCS, left coronary sinus; $L / R \mathrm{com}$, left/right commissure; $R C S$, right coronary sinus; $R / \mathrm{N}$ com, right/non commissure.

reported the external root height or root base thickness. Three studies report the internal root height or volume of the sinus of Valsalva in pressurized and chemically fixed aortic roots. In those studies, the LCS was systematically found to be the smallest sinus and the RCS was found to be alternatively larger, equal to, or smaller than the NCS. ${ }^{3,22,23}$ Based on the differences in sinuses height, 2 of these studies report the presence of a tilt angle of $5.5^{\circ}$ or $11^{\circ}$, respectively, between the BR and STJ planes. $^{22,23}$ In our study, the internal root height was relatively similar between the 3 sinuses. However, the nonplanar nature of the VAJ makes the external root height significantly greater on the side of the NCS and LCS compared with the RCS.

The clinical implications of this study relate essentially to annuloplasty techniques applied to the external aspect of the aortic root (ie, valve-sparing reimplantation and external ring annuloplasty). In external annuloplasty techniques, the graft or the ring is fixed around the root base with several sutures placed from the inside below cusp insertion. ${ }^{21,24}$
Obviously, incomplete proximal root dissection will impede placement of the device down to the BR level. In this study, we have shown that a complete proximal root dissection allows the BR to be reached systematically along the NCS, non/left commissure, and LCS (Figure 2).

At the left/right commissure, the VAJ is on average 4.6 $\mathrm{mm}$ above the BR. However, at this level the ventricular muscle terminates like a crest with its external aspect oblique caudally and laterally. This anatomy allows approximation externally at the level of the BR. In the reimplantation technique, investigators generally recommend not following exactly the BR with the proximal suture line at this commissure but to go up 3 to $4 \mathrm{~mm}$ above the BR. ${ }^{19,21}$

At the RCS, the VAJ is in on average $2.4 \mathrm{~mm}$ above the $\mathrm{BR}$. The base of the sinus is adherent to the myocardium of the right ventricle, which bulges cranially and laterally. More caudal dissection is not possible at this level without entering the right ventricle or the interventricular septum. As a result, any external annuloplasty device risks being 
placed above the BR if the sutures exit at the VAJ level. It is not known how much displacement of the device is tolerated before valve function and BR stabilization are significantly impaired. Theoretically, the way to reach the BR in patients with a high VAJ level ( $>4$ to $5 \mathrm{~mm}$ ) is to open the right ventricle. However, in valve-sparing reimplantation, the graft can be brought down and approximate the BR level without entering the right ventricle. Therefore, the stitches of the proximal suture line must exit 5 to $10 \mathrm{~mm}$ lateral to the VAJ, through the right ventricular muscle. In this way, a small lateral portion of the right ventricle is plicated downward when the sutures are tied and the graft is pulled caudally near to the BR level. With this maneuver, the thickness of the root base included in the annuloplasty may be greater than the thickness of the muscular inclusion measured in this study because it includes a layer of right ventricular muscle in addition to the interventricular septum.

At the right/non commissure, the lower portion of the interleaflet triangle comprises the membranous septum. At the outside of the commissure, the VAJ is composed of the wall of the right atrium joining the aortic root wall 2.5 $\mathrm{mm}$ above the BR. The VAJ delineates the upper contour of the membranous septum. As in the left/right commissure, the proximal suture line of the reimplantation technique should not follow the BR but a curve going up 3 to $4 \mathrm{~mm}$ above the BR to avoid the conduction bundles and the membranous septum. $^{21}$

The appropriate height where the commissures need to be implanted onto the graft is often considered as a difficult step in the valve-sparing reimplantation technique. Misjudgment in commissural implantation can lead to valve distortion and prolapse with early recurrence of regurgitation. ${ }^{25}$ David $^{26}$ has reported that the 3 commissures are of different heights; the left/right commissure is generally shorter than the other 2 commissures. In this study, we showed that the external heights of the commissures are different, with a relative height of $0.99,0.72$, and 0.88 for the left/non, right/non, and left/right commissures, respectively. Therefore, to orient commissure implantation, we have already proposed that the height of the 3 commissures should be measured and translated onto the graft. ${ }^{21}$

The root base thickness reported in this study can help in the sizing of annuloplasty devices. For example, with a mean wall thickness of $3 \mathrm{~mm}$, a graft of $30 \mathrm{~mm}$ diameter will reduce the VAJ diameter to at least $24 \mathrm{~mm}$ (30 $[2 \times 3])$ or more inasmuch as the preoperative diameter of the BR diameter is large and if proximal sutures compress the graft.

\section{Limitations}

Our study has several limitations, mainly related to the nature of aortic root specimens and the method of analysis. We analyzed the anatomic characteristics of tricuspid aortic valves with normal aspect or with some calcific degeneration. Aortic valves with root aneurysm or regurgitation and bicuspid aortic valves, representing the main indications for aortic valve repair, were not analyzed and may present different anatomical characteristics than the ones reported in this study. The differences observed with other anatomical studies can be related to the method of preservation and measure. We have chosen to analyze unfixed and unpressurized specimens to mimic the surgical conditions for external root preparation and to avoid eventual alteration of the thickness and stiffness of myocardial tissues by chemical fixation. Therefore, tissue elasticity may have introduced a nonsystematic error into the different measurements. The specimens were analyzed ex vivo, and separate from the heart, these conditions can also affect the anatomical characteristics of the aortic valve and root. Additional studies on normal and pathologic aortic roots are needed to confirm the anatomical characteristics found in this study and to define whether they are similar or not in the pathologies for which aortic valve repair is indicated.

\section{CONCLUSIONS}

Although the internal aspect of the aortic root is relatively symmetric, the external aspect of the root is more asymmetric. This asymmetry is related to the threedimensional shape of the VAJ which is 2.3 to $4.6 \mathrm{~mm}$ above the level of the basal ring from the left/right commissure to the right/non commissure. As a consequence, the external height of the non/left commissure is greater than the other 2 commissures. The root base thickness is variable along the circumference with a mean of $3.2 \mathrm{~mm}$. The mean width of the muscular inclusion at the base of RCS is $6.2 \mathrm{~mm}$. These findings should be taken into consideration when performing aortic valve-sparing reimplantation or aortic valve annuloplasty.

\section{References}

1. Sands MP, Rittenhouse EA, Mohri H, Merendino KA. An anatomical comparison of human pig, calf, and sheep aortic valves. Ann Thorac Surg. 1969;8:407-14

2. Swanson M, Clark RE. Dimensions and geometric relationships of the human aortic valve as a function of pressure. Circ Res. 1974;35:871-82.

3. Silver MA, Roberts WC. Detailed anatomy of the normally functioning aortic valve in hearts of normal and increased weight. Am J Cardiol. 1985;55:454-61.

4. Roman MJ, Devereux RB, Kramer-Fox R, O'Loughlin J. Two-dimensional echocardiographic aortic root dimensions in normal children and adults. Am J Cardiol. 1989;64:507-12.

5. Anderson RH, Devine WA, Ho SY, Smith A, McKay R. The myth of the aortic annulus: the anatomy of the subaortic outflow tract. Ann Thorac Surg. 1991;52: 640-6.

6. Kunzelman KS, Grande KJ, David TE, Cochran RP, Verrier ED. Aortic root and valve relationships. Impact on surgical repair. J Thorac Cardiovasc Surg. 1994; 107:162-70.

7. Sutton JP III, Ho SY, Anderson RH. The forgotten interleaflet triangles: a review of the surgical anatomy of the aortic valve. Ann Thorac Surg. 1995;59:419-27.

8. Hanke T, Charitos EI, Stierle U, Robinson D, Gorski A, Sievers HH, et al. Factors associated with the development of aortic valve regurgitation over time after two different techniques of valve-sparing aortic root surgery. J Thorac Cardiovasc Surg. 2009; 137:314-9.

9. Aicher D, Kunihara T, Abou Issa O, Brittner B, Graber S, Schafers HJ. Valve configuration determines long-term results after repair of the bicuspid aortic valve. Circulation. 2011;123:178-85. 
10. de Kerchove L, Boodhwani M, Glineur D, Vandyck M, Vanoverschelde JL, Noirhomme P, et al. Valve sparing-root replacement with the reimplantation technique to increase the durability of bicuspid aortic valve repair. $J$ Thorac Cardiovasc Surg. 2011;142:1430-8.

11. Kunihara T, Aicher D, Rodionycheva S, Groesdonk HV, Langer F, Sata F, et al. Preoperative aortic root geometry and postoperative cusp configuration primarily determine long-term outcome after valve-preserving aortic root repair. $J$ Thorac Cardiovasc Surg. 2012;143:1389-95.

12. Navarra E, El Khoury G, Glineur D, Boodhwani M, Van Dyck M, Vanoverschelde JL, et al. Effect of annulus dimension and annuloplasty on bicuspid aortic valve repair. Eur J Cardiothorac Surg. 2013;44:316-22; discussion 322-23.

13. Lansac E, Di Centa I, Sleilaty G, Crozat EA, Bouchot O, Hacini R, et al. An aortic ring: from physiologic reconstruction of the root to a standardized approach for aortic valve repair. J Thorac Cardiovasc Surg. 2010;140:S28-35; discussion S45-51.

14. Mazzitelli D, Nobauer C, Rankin JS, Badiu CC, Dorfmeister M, Crooke PS, et al. Early results of a novel technique for ring-reinforced aortic valve and root restoration. Eur J Cardiothorac Surg. 2014;45:426-30.

15. Aicher D, Schneider U, Schmied W, Kunihara T, Tochii M, Schafers HJ. Early results with annular support in reconstruction of the bicuspid aortic valve. $J$ Thorac Cardiovasc Surg. 2013;145:S30-4.

16. Richardt D, Bucsky B, Charitos EI, Sievers HH, Scharfschwerdt M. A novel rigid annuloplasty ring for aortic valve reconstruction: an in vitro investigation. Ann Thorac Surg. 2014;97:811-5.

17. de Kerchove L, Vismara R, Mangini A, Fiore GB, Price J, Noirhomme P, et al. In vitro comparison of three techniques for ventriculo-aortic junction annuloplasty. Eur J Cardiothorac Surg. 2012;41:1117-23; discussion 1123-24.
18. Miller DC. Valve-sparing aortic root replacement in patients with the Marfan syndrome. J Thorac Cardiovasc Surg. 2003;125:773-8.

19. David TE, Maganti M, Armstrong S. Aortic root aneurysm: principles of repair and long-term follow-up. J Thorac Cardiovasc Surg. 2010;140:S14-9; discussion S45-51.

20. Ho SY. Structure and anatomy of the aortic root. Eur J Echocardiogr. 2009;10: i3-10.

21. Boodhwani M, de Kerchove L, El Khoury G. Aortic root replacement using the reimplantation technique: tips and tricks. Interact Cardiovasc Thorac Surg. 2009 8:584-6.

22. Choo SJ, McRae G, Olomon JP, St George G, Davis W, Burleson-Bowles CL, et al. Aortic root geometry: pattern of differences between leaflets and sinuses of Valsalva. J Heart Valve Dis. 1999;8:407-15.

23. Berdajs D, Lajos P, Turina M. The anatomy of the aortic root. Cardiovasc Surg. 2002;10:320-7.

24. Lansac E, Di Centa I, Varnous S, Rama A, Jault F, Duran CM, et al. Externa aortic annuloplasty ring for valve-sparing procedures. Ann Thorac Surg. 2005 79:356-8.

25. Giebels C, Aicher D, Kunihara T, Rodionycheva S, Schmied W, Schafers HJ. Causes and management of aortic valve regurgitation after aortic valve reimplantation. J Thorac Cardiovasc Surg. 2013;145:774-80.

26. David TE. Sizing and tailoring the Dacron graft for reimplantation of the aortic valve. J Thorac Cardiovasc Surg. 2005;130:243-4.

Key words: aortic valve anatomy, aortic insufficiency, aortic valve repair, valve-sparing surgery, annuloplasty

Access to The Journal of Thoracic and Cardiovascular Surgery Online is reserved for print subscribers!

Full-text access to The Journal of Thoracic and Cardiovascular Surgery Online is available for all print subscribers. To activate your individual online subscription, please visit The Journal of Thoracic and Cardiovascular Surgery Online, point your browser to http://www.mosby.com/itcvs, follow the prompts to activate your online access, and follow the instructions. To activate your account, you will need your subscriber account number, which you can find on your mailing label (note: the number of digits in your subscriber account number varies from 6 to 10 ). See the example below in which the subscriber account number has been circled:

\section{Sample mailing label}

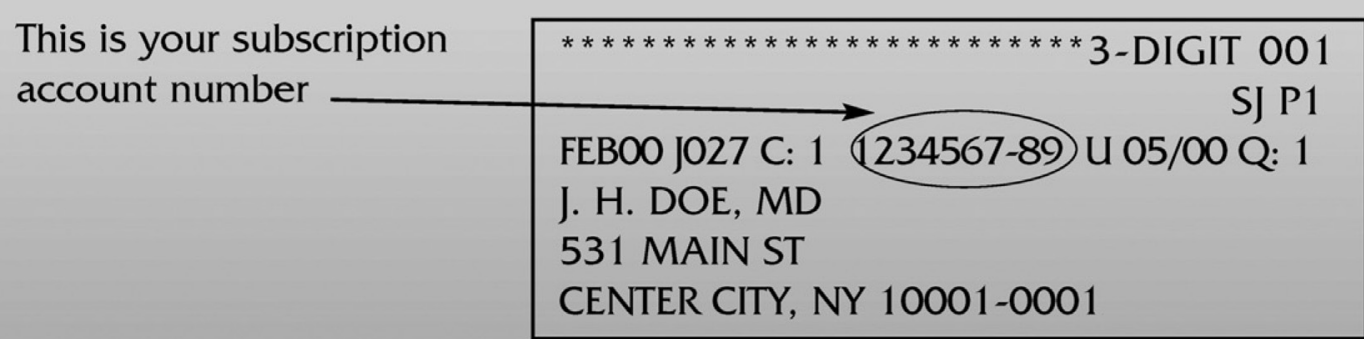

Personal subscriptions to The Journal of Thoracic and Cardiovascular Surgery Online are for individual use only and may not be transferred. Use of The Journal of Thoracic and Cardiovascular Surgery Online is subject to agreement to the terms and conditions as indicated online. 